\title{
Critical weight loss is a major prognostic indicator for disease-specific survival in patients with head and neck cancer receiving radiotherapy
}

\begin{abstract}
J A E Langius *,1, S Bakker ${ }^{1}$, D H F Rietveld ${ }^{2}$, H M Kruizenga ${ }^{1}$, J A Langendijk ${ }^{3}$, P J M Weijs ${ }^{1}$ and C R Leemans ${ }^{4}$ ${ }^{1}$ Department of Nutrition and Dietetics, Internal Medicine, VU University Medical Center, PO Box 7057, 1007 MB Amsterdam, The Netherlands; ${ }^{2}$ Department of Radiation Oncology, VU University Medical Center, PO Box 7057, 1007 MB Amsterdam, The Netherlands; ${ }^{3}$ Department of Radiation Oncology, University Medical Center Groningen, University of Groningen, PO Box 30.001, 9700 RB Groningen, The Netherlands and ${ }^{4}$ Department of Otolaryngology/Head and Neck Surgery, VU University Medical Center, PO Box 7057, 1007 MB Amsterdam, The Netherlands
\end{abstract}

Background: Pre-treatment weight loss (WL) is a prognostic indicator for overall survival $(\mathrm{OS})$ in head and neck cancer (HNC) patients. This study investigates the association between WL before or during radiotherapy and disease-specific survival (DSS) in HNC patients.

Methods: In 1340 newly diagnosed HNC patients, weight change was collected before and during (adjuvant) radiotherapy with curative intent. Critical WL during radiotherapy was defined as $>5 \%$ WL during radiotherapy or $>7.5 \%$ WL until week 12 . Differences in 5-year OS and DSS between WL groups were analysed by Cox's regression with adjustments for important socio-demographic and tumour-related confounders.

Results: Before radiotherapy, 70\% of patients had no WL, $16 \%$ had $\leqslant 5 \% \mathrm{WL}, 9 \%$ had $>5-10 \% \mathrm{WL}$, and $5 \%$ had $>10 \%$ WL. Fiveyear OS and DSS rates for these groups were $71 \%, 59 \%, 47 \%$, and $42 \%(P<0.001)$, and $86 \%, 86 \%, 81 \%$, and $71 \%$, respectively $(P<0.001)$. After adjustment for potential confounders, $>10 \% \mathrm{WL}$ before radiotherapy remained significantly associated with a worse OS (HR 1.7; 95\% Cl 1.2-2.5; $P=0.002$ ) and DSS (HR 2.1; 95\% Cl 1.2-3.5; $P=0.007)$. The 5-year OS and DSS rates for patients with critical WL during radiotherapy were $62 \%$ and $82 \%$, compared with $70 \%$ and $89 \%$ for patients without critical WL $(P=0.01$; $P=0.001)$. After adjustment, critical WL during radiotherapy remained significantly associated with a worse DSS (HR $1.7 ; 95 \% \mathrm{Cl}$ $1.2-2.4 ; P=0.004)$.

Conclusion: Weight loss both before and during radiotherapy are important prognostic indicators for 5-year DSS in HNC patients. Randomised studies into the prognostic effect of nutritional intervention are needed.

Patients with head and neck cancer are predominantly at risk for malnutrition due to anorexia, sequelae of the treatment that hamper food intake (e.g., xerostomia or dysphagia) and metabolic alterations as a result of inflammation, which can be induced by the tumour or the therapy (Van Cutsem and Arends, 2005; Baracos, 2006; Richey et al, 2007; Silver et al, 2007). Malnutrition is a subacute or chronic state in which a combination of varying degrees of undernutrition and inflammatory activity has led to a change in body composition and diminished function (Soeters et al, 2008). Weight loss is one of the main symptoms of malnutrition. 
Weight loss is a frequently observed problem among patients with head and neck cancer (Jager-Wittenaar et al, 2007; Ehrsson et al, 2010). Malnutrition before treatment may be seen in as high as $63 \%$ of patients, and its prevalence is associated with the location of the tumour (Nayel et al, 1992; Argiris et al, 2004; Unsal et al, 2006; Jager-Wittenaar et al, 2007; Capuano et al, 2010, 2008; Langius et al, 2010). During treatment, many patients develop treatment-related toxicities, of which dysphagia caused by mucositis is one of the most prominent. These acute toxicities result in discomfort and difficulties with eating. During radiotherapy, the prevalence of malnutrition rises to $41-88 \%$ (Nayel et al, 1992; Unsal et al, 2006; Langius et al, 2010). Sequelae of radiation therapy and weight loss may continue for several weeks after completion of radiotherapy (Langius et al, 2010; Mehanna et al, 2010).

It has been demonstrated that weight loss before treatment is a prognostic indicator for overall survival (Brookes, 1985; Pugliano et al, 1999; Van Bokhorst-de van der Schueren et al, 1999; Nguyen and Yueh, 2002; De Cassia Braga et al, 2003; Argiris et al, 2004; Van Den Broek et al, 2004; Pedruzzi et al, 2008).

As the association between weight loss before or during radiotherapy and disease-specific survival in patients with head and neck cancer is unclear, we set out to investigate this.

\section{MATERIALS AND METHODS}

Study population. A consecutive cohort of head and neck cancer patients treated by radiotherapy between January 2000 and January $2009(n=1799)$ was investigated for inclusion in this study. Main inclusion criterion was curative radiotherapy, either as sole treatment (with or without chemotherapy) or postoperatively. Patients younger than 18 years, patients with a tumour of the ear, skin, or oesophagus, and those with previous cancer history were excluded (Figure 1). The final study population was composed of 1340 patients. This study was approved by the Medical Ethics Committee of the VU University Medical Center Amsterdam.
Radiotherapy. All patients were treated on 6-MV linear accelerators (Varian Medical Systems, Inc., Palo Alto, CA, USA), immobilised in the supine position by the use of individually designed facial masks. From January 2000, conventional threedimensional conformal radiotherapy was applied until the clinical introduction of parotid gland sparing IMRT in October 2004. In the primary irradiated patients, the tumour and lymph-node metastases were treated with 2 Gy per fraction up to a total dose of $70 \mathrm{~Gy}$. A dose of $46 \mathrm{~Gy}$ in daily fractions of $2 \mathrm{~Gy}$ (or an equivalent dose of 35 daily fractions of $1.55 \mathrm{~Gy}$ ) was given to the elective nodal areas. Patients treated with postoperative radiotherapy received 2Gy daily fractions at the primary site and nodal metastases to a total dose of 56 or $66 \mathrm{~Gy}$, depending on the surgical margin status and the presence of extranodal spread. Again the elective dose was $46 \mathrm{~Gy}$ in 2-Gy daily fractions (or an equivalent dose of 28 fractions of $1.8 \mathrm{~Gy}$ or 33 fractions of $1.65 \mathrm{~Gy}$ ). In the case of concomitant chemoradiation, three cycles of cisplatin $100 \mathrm{mg} \mathrm{m}^{-2}$ were given on days 1,22 , and 43 .

From the start of radiotherapy, patients received dietary counselling to achieve individual nutritional requirements. If nutritional requirements could not be reached by regular food products, then energy-enriched oral nutritional supplements and/ or enteral tube feeding by nasogastric tube or percutaneous endoscopic gastrostomy were subscribed.

Data collection. All data were prospectively collected. At baseline, patient and tumour characteristics were recorded. Weight loss before radiotherapy was recalled by the radiotherapist and, based on the equation (current weight - usual weight)/usual weight $\times 100 \%$, categorised into four groups: no weight loss, $\leqslant 5 \%$ weight loss, $>5-10 \%$ weight loss and $>10 \%$ weight loss. Body weight was measured at the start of radiotherapy ( \pm 7 days) and weekly thereafter until the eighth week, and at 12 weeks after the start of radiotherapy (labelled as 'during radiotherapy'). Body weight was measured by wearing light indoor clothing and shoes on a digital electronic scale (Seca (Hamburg, Germany), Alpha 770 ) to the nearest $0.1 \mathrm{~kg}$. Weight was corrected for clothing and shoes by subtracting $2.0 \mathrm{~kg}$ for men and $1.3 \mathrm{~kg}$ for women (Frank and Dunlop, 2000).

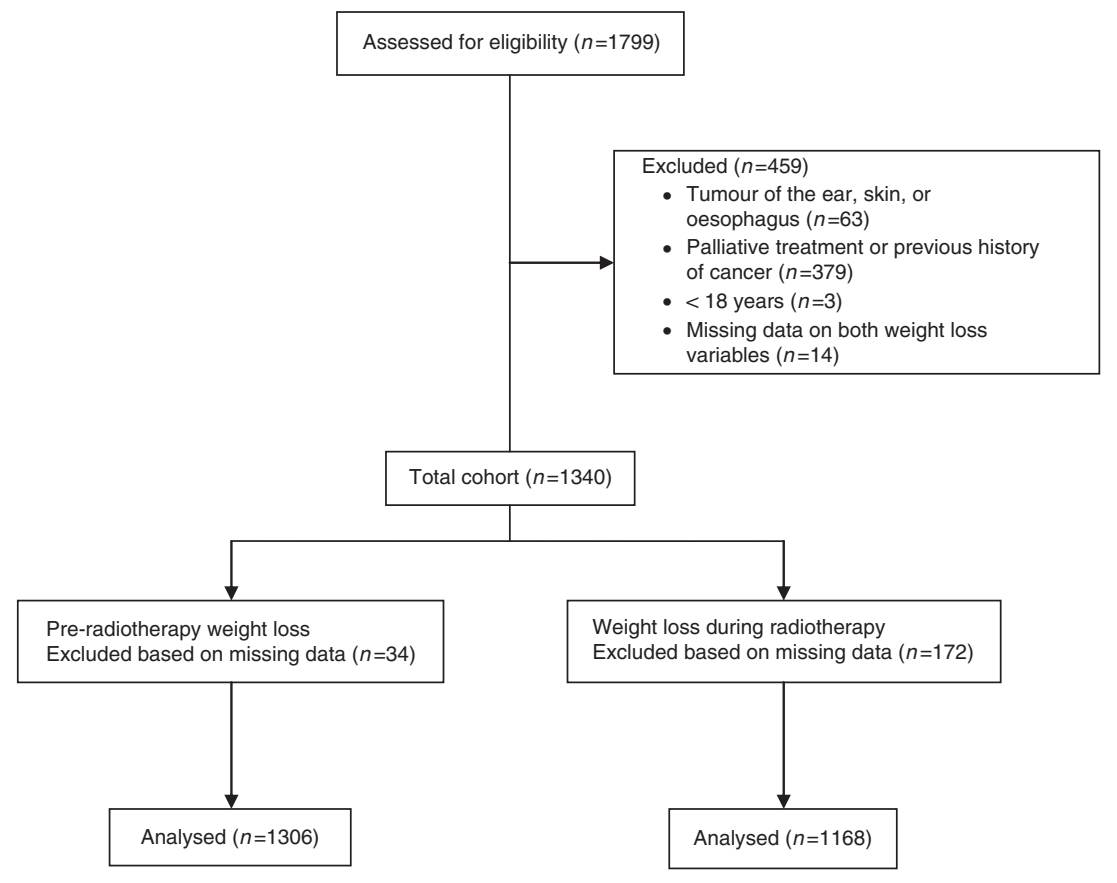

Figure 1. Flowchart. 
Definitions. Critical weight loss was defined as body weight loss of $>5 \%$ from the start of radiotherapy until week 8 or $>7.5 \%$ until week 12 according to the international consensus statement (White et al, 2012). Because we earlier observed that acute radiotherapy induced toxicity and weight loss arise after 2 weeks of radiotherapy (Langius et al, 2010), the time span for critical weight loss during radiotherapy was expected to be the last month of radiotherapy.

Overall survival was defined as the time elapsed between the start of radiotherapy and the date of death of any cause, or if the patient was still alive, and 5 years after the start of radiotherapy. Disease-specific survival was defined as the time elapsed between the start of radiotherapy and the date of death due to cancer, or if the patient was still alive, and 5 years after the start of radiotherapy. Patients who were lost to follow-up within 5 years were censored at their last date of follow-up. In the analysis of disease-specific survival, deaths due to causes other than head and neck cancer were treated as censored observations at the time of death.

Statistical analysis. To test differences in patient, tumour, and treatment characteristics between survivors and non-survivors, $\chi^{2}$ tests were used regarding gender, tumour location, TNM stage (Edge et al, 2010), baseline WHO performance score, weight loss before radiotherapy, treatment modality, and radiotherapy on the neck nodes, and independent $t$ test was used regarding age.

Survival curves were generated using the method of KaplanMeier. The log-rank test was used to examine the difference in overall and disease-specific survival between weight loss groups. Cox's proportional hazard models were used to build multivariate (i.e., adjusted) models. Relevant factors influencing both weight loss and the survival period were selected a priori, based on the literature. Potential confounder variables for the association between weight loss before radiotherapy and overall and diseasespecific survival were age, gender, tumour location (oral cavity, oropharynx, nasopharynx, hypopharynx, larynx, nasal cavity and paranasal sinuses, major salivary glands, and unknown primary), TNM stage (I, II, III, and IV), prior head and neck surgery, and baseline WHO performance score $(0,1$, and $2 / 3)$. For the association between weight loss during radiotherapy and overall and disease-specific survival, we additionally adjusted for weight loss before radiotherapy (no weight loss, $\leqslant 5 \%$ weight loss, $>5-10 \%$ weight loss, and $>10 \%$ weight loss), treatment modality (RT alone, RT + surgery, and RT + chemotherapy \pm surgery), and radiotherapy on the neck nodes (none, unilateral, and bilateral). We attempted to adjust for comorbidity by the Adult Comorbidity Evaluation-27 (ACE-27) test (Paleri and Wight, 2002), but the scores were available only in patients receiving chemoradiotherapy. Therefore, a subgroup analyses was performed to analyse the effect of comorbidity on the association between weight loss and overall and disease-specific survival.

Interaction between weight loss and gender or age with respect to overall and disease-specific survival was investigated, but both were no effect modifiers. Proportional hazard assumptions for each model was investigated and confirmed by testing the constancy over time of the log-hazard ratio for each model. $P$-values of $<0.05$ were considered as statistically significant. Analyses were performed using the SPSS software (version 20.0.0; 2011 IBM Corporation, New York, NY, USA).

\section{RESULTS}

The majority of patients (70\%) were male. The mean age was $61.4 \pm 12.0$ years, and ranged from 19 to 96 years. Tumours were mainly located at the larynx and oropharynx. Eighteen percent of patients had stage I tumours, $21 \%$ stage II, $18 \%$ stage III, whereas $43 \%$ had stage IV tumours. Slightly more than half of the patients received a combined modality treatment (Table 1 ).

\begin{tabular}{|c|c|c|c|c|}
\hline & $\begin{array}{c}\text { All patients, } \\
\text { n (\%) }\end{array}$ & $\begin{array}{l}\text { Alive, } \\
\text { n (\%) }\end{array}$ & $\begin{array}{l}\text { Dead, } \\
\text { n (\%) }\end{array}$ & $\boldsymbol{P}$-value \\
\hline & $1340(100)$ & $869(65)$ & 471 (35) & \\
\hline \multicolumn{5}{|l|}{ Gender } \\
\hline $\begin{array}{l}\text { Male } \\
\text { Female }\end{array}$ & $\begin{array}{l}937(70) \\
403(30)\end{array}$ & $\begin{array}{l}595(64) \\
274(68)\end{array}$ & $\begin{array}{l}342(36) \\
129(32)\end{array}$ & 0.11 \\
\hline \multicolumn{5}{|l|}{ Age } \\
\hline Mean (s.d.) & $61.4 \pm 12.0$ & $60.0 \pm 11.7$ & $64.1 \pm 12.1$ & $<0.001$ \\
\hline
\end{tabular}

Tumour location

\begin{tabular}{|l|c|c|c|c|}
\hline Oral cavity & $242(18)$ & $140(58)$ & $102(42)$ & $<0.001$ \\
Oropharynx & $310(23)$ & $189(61)$ & $121(39)$ & \\
Nasopharynx & $47(4)$ & $33(70)$ & $14(30)$ & \\
Hypopharynx & $74(6)$ & $22(30)$ & $52(70)$ & \\
Larynx & $436(33)$ & $321(74)$ & $115(26)$ & \\
Nasal cavity and & $106(8)$ & $77(73)$ & $29(27)$ & \\
paranasal sinuses & & & & \\
Major salivary glands & $75(6)$ & $53(71)$ & $22(29)$ & \\
Unknown primary & $50(4)$ & $34(68)$ & $16(32)$ & \\
\hline
\end{tabular}

TNM stage

\begin{tabular}{|l|l|l|l|l|}
\hline I & $232(18)$ & $193(83)$ & $39(17)$ & $<0.001$ \\
II & $269(21)$ & $206(77)$ & $63(23)$ & \\
III & $232(18)$ & $159(68)$ & $73(32)$ & \\
IV & $550(43)$ & $267(48)$ & $283(52)$ & \\
\hline
\end{tabular}

Weight loss before RT

\begin{tabular}{|l|c|c|c|c|}
\hline None & $911(70)$ & $642(71)$ & $269(30)$ & $<0.001$ \\
$\leqslant 5 \%$ & $215(16)$ & $126(59)$ & $89(41)$ & \\
$>5-10 \%$ & $111(9)$ & $52(47)$ & $59(53)$ & \\
$>10 \%$ & $69(5)$ & $29(42)$ & $40(58)$ & \\
\hline
\end{tabular}

WHO performance score

\begin{tabular}{|l|c|c|c|c|}
\hline 0 & $399(38)$ & $305(76)$ & $94(24)$ & $<0.001$ \\
1 & $533(51)$ & $333(63)$ & $200(37)$ & \\
$2 / 3$ & $116(11)$ & $44(38)$ & $72(62)$ & \\
\hline
\end{tabular}

Treatment modality

\begin{tabular}{|l|c|c|c|c|}
\hline RT alone & $591(44)$ & $403(68)$ & $188(32)$ & 0.01 \\
Surgery+RT & $485(36)$ & $313(65)$ & $172(35)$ & \\
ChemoRT & $251(19)$ & $143(57)$ & $108(43)$ & \\
Surgery+ ChemoRT & $13(1)$ & $10(77)$ & $3(23)$ & \\
\hline
\end{tabular}

RT dose

\begin{tabular}{|c|c|c|c|c|}
\hline Median & 68 & 68 & 70 & 0.09 \\
\hline \multicolumn{5}{|c|}{ RT on the neck nodes } \\
\hline No & $350(26)$ & 275 (79) & $75(21)$ & $<0.001$ \\
\hline Unilateral & $225(17)$ & $162(72)$ & $63(28)$ & \\
\hline Bilateral & $762(57)$ & $432(57)$ & $330(43)$ & \\
\hline
\end{tabular}

Abbreviations: $\mathrm{RT}=$ radiotherapy; s.d. = standard deviation; TNM = tumour, node, metastasis; $\mathrm{WHO}=$ world health organisation. $P$-values $<0.05$ are shown in bold. $P$-values were obtained by independent $t$-test or $\chi^{2}$ tests.

Four-hundred and seventy-one patients (35\%) died within 5 years. No significant difference was found between the survivors and the non-survivors regarding gender. There were significant differences between the survivors and the non-survivors regarding age, tumour location, TNM stage, weight loss before radiotherapy, WHO performance score, treatment modality, and radiotherapy on the neck nodes (Table 1). 
Weight loss before radiotherapy. Before radiotherapy, $70 \%$ of patients had no weight loss, $16 \%$ had $\leqslant 5 \%$ weight loss, $9 \%$ had $>5-10 \%$ weight loss, and $5 \%$ had $>10 \%$ weight loss (Table 1 ). Five-year overall survival rates for these groups were $71 \%, 59 \%$, $47 \%$, and $42 \%$, respectively (log rank: $P<0.001$; Figure 2 ). Fiveyear disease-specific survival rates for these groups were $86 \%, 86 \%$, $81 \%$, and $71 \%$, respectively (log rank: $P<0.001$ ).

The unadjusted Cox's regression analysis (Table 2) showed that weight loss before radiotherapy (of any category) was significantly associated with a worse overall survival. In addition, we found that the two most severe weight loss categories $(>5-10 \%$ and $>10 \%$ weight loss) were significantly associated with a worse disease-

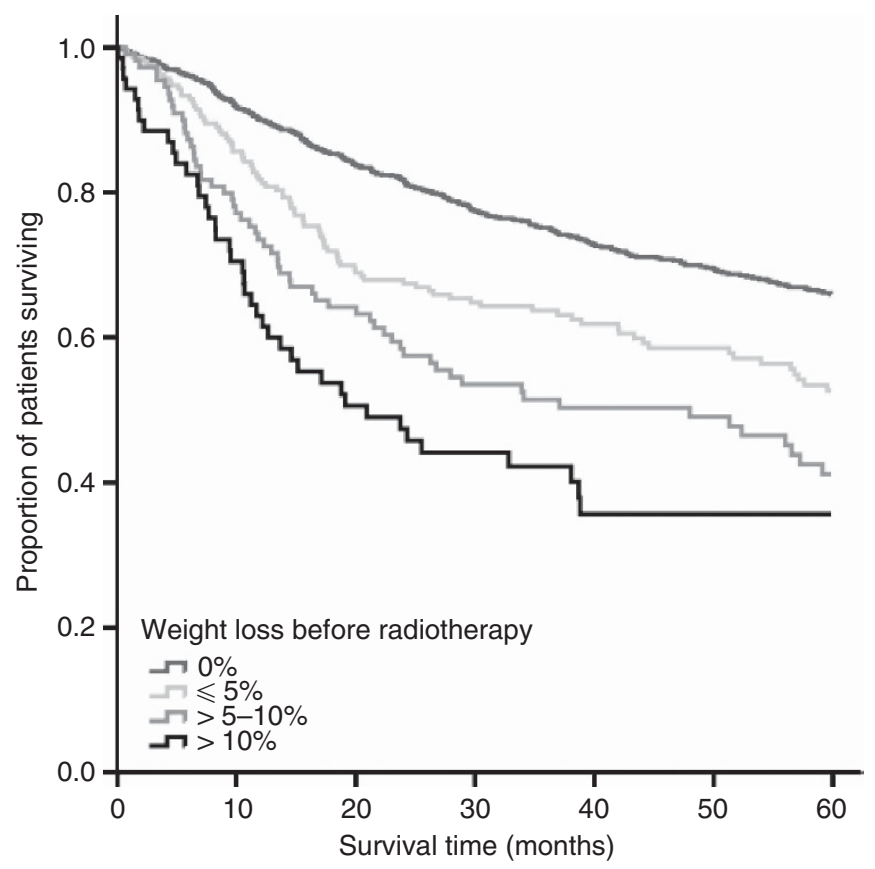

Figure 2. Kaplan-Meier survival plot of overall survival by weight loss category before radiotherapy (log-rank test: $P<0.001$ ).

Table 2. Cox regression analyses of the association between weight loss before radiotherapy and 5-year overall and disease-specific survival

\begin{tabular}{|c|c|c|c|c|}
\hline & \multicolumn{2}{|c|}{ Crude model } & \multicolumn{2}{|c|}{ Adjusted model ${ }^{a}$} \\
\hline & HR $(95 \% \mathrm{Cl})$ & $\boldsymbol{P}$-value & $\mathrm{HR}(95 \% \mathrm{Cl})$ & $P$-value \\
\hline \multicolumn{5}{|c|}{ Overall survival } \\
\hline $\begin{array}{l}\leqslant 5 \% \mathrm{WL} \\
>5-10 \% \mathrm{WL} \\
>10 \% \mathrm{WL}\end{array}$ & $\begin{array}{l}1.6(1.3-2.0) \\
2.3(1.7-3.0) \\
3.1(2.2-4.3)\end{array}$ & $\begin{array}{l}<0.001 \\
<0.001 \\
<0.001\end{array}$ & $\begin{array}{l}1.1(0.9-1.4) \\
1.4(1.2-1.9) \\
1.7(1.2-2.5)\end{array}$ & $\begin{array}{l}0.388 \\
0.026 \\
0.002\end{array}$ \\
\hline \multicolumn{5}{|c|}{ Disease-specific survival } \\
\hline $\begin{array}{l}\leqslant 5 \% \mathrm{WL} \\
>5-10 \% \mathrm{WL} \\
>10 \% \mathrm{WL}\end{array}$ & $\begin{array}{l}1.1(0.8-1.7) \\
1.7(1.1-2.7) \\
3.3(2.1-5.3)\end{array}$ & $\begin{array}{c}0.570 \\
0.021 \\
<0.001\end{array}$ & $\begin{array}{l}0.9(0.6-1.4) \\
1.3(0.8-2.1) \\
2.1(1.2-3.5)\end{array}$ & $\begin{array}{l}0.647 \\
0.333 \\
\mathbf{0 . 0 0 7}\end{array}$ \\
\hline \multicolumn{5}{|c|}{ 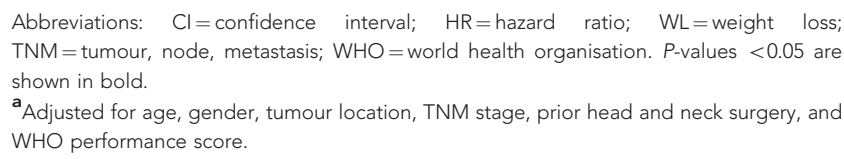 } \\
\hline
\end{tabular}

specific survival. After adjustment for all previously mentioned potential confounders, $>10 \%$ weight loss before radiotherapy remained significantly associated with a worse overall (HR 1.7; 95\% CI $1.2-2.5 ; P=0.002$ ) and disease-specific survival (HR 2.1; $95 \%$ CI $1.2-3.5 ; P=0.007$ ) (Table 2).

In the subgroup of chemoradiotherapy, comorbidity nearly affected the association between weight loss before chemoradiotherapy and overall survival ( $>10 \%$ weight loss HR 3.3, 95\% CI $1.7-6.7, P=0.001$; $>5-10 \%$ weight loss HR 2.3 , 95\% CI $1.3-4.2$, $P=0.005$; $\leqslant 5 \%$ weight loss HR $1.8 ; 95 \%$ CI $1.0-3.2 ; P=0.041$ ). Comorbidity was not significantly associated with disease-specific survival.

Weight loss during radiotherapy. Critical weight loss during radiotherapy was observed in $57 \%$ of patients. Mean weight loss during radiotherapy was $4.1( \pm 4.7) \mathrm{kg}$, which corresponded to 5.4 ( \pm 6.1$) \%$ of body weight. On average, patients with critical weight loss lost $9.0( \pm 4.8) \%$ of their body weight.

Patients with critical weight loss had lower 5-year overall survival rates than patients without critical weight loss during radiotherapy (survival rates: $62 \%$ vs $70 \%$; log rank: $P=0.01$ ). However, the adjusted association was no longer statistically significant (HR 1.1; 95\% CI 0.9-1.4; $P=0.295$ ) (Table 3).

The 5-year disease-specific survival rate for patients with critical weight loss was $82 \%$, compared with $89 \%$ for patients without critical weight loss (HR 1.7; 95\% CI 1.2-2.3; $P=0.001$; Figure 3). After adjustment for all confounders, disease-specific survival was still significantly worse for patients with critical weight loss during radiotherapy (HR 1.7; 95\% CI 1.2-2.4; $P=0.004$ ) (Table 3).

In the subgroup of chemoradiotherapy, all patients who died because of head and neck cancer had critical weight loss during therapy. Therefore, no further subgroup analyses were possible.

Patients who were excluded because of missing baseline weight (Figure 1), had a shorter overall survival time compared with the included patients (log rank: $P=0.009$ ). Disease-specific survival was not significantly different.

\section{DISCUSSION}

Weight loss as a consequence of (chemo)radiotherapy is a common problem in patients with head and neck cancer (Langius et al, 2013). However, little is known about its prognostic effect on disease-specific survival. This study shows that critical weight loss during radiotherapy is independently associated with a 1.7 times higher risk of dying of head and neck cancer.

Table 3. Cox regression analyses of the association between critical weight loss during radiotherapy and 5-year overall and disease-specific survival

\begin{tabular}{|l|c|c|c|c|}
\cline { 2 - 5 } \multicolumn{2}{|c|}{ Crude model } & \multicolumn{2}{c|}{ Adjusted model } \\
\hline & HR $(\mathbf{9 5 \%}$ Cl) & P-value & HR (95\% Cl) & P-value \\
\hline & $1.3(1.1-1.6)$ & $\mathbf{0 . 0 1 0}$ & $1.1(0.9-1.4)$ & 0.295 \\
\hline $\begin{array}{l}\text { Overall survival } \\
\text { Disease-specific } \\
\text { survival }^{\mathbf{b}}\end{array}$ & $1.7(1.2-2.3)$ & $\mathbf{0 . 0 0 1}$ & $1.7(1.2-2.4)$ & $\mathbf{0 . 0 0 4}$ \\
\hline
\end{tabular}

Abbreviations: $\mathrm{Cl}=$ confidence interval; $\mathrm{HR}=$ hazard ratio; $\mathrm{TNM}$, tumour, node, metastasis; $\mathrm{WHO}=$ world health organisation. $P$-values $<0.05$ are shown in bold.

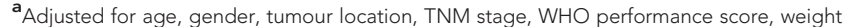
loss before radiotherapy, radiotherapy on the neck nodes and treatment modality.

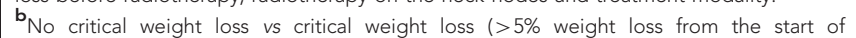
radiotherapy until week 8 and/or $>7.5 \%$ until week 12). 


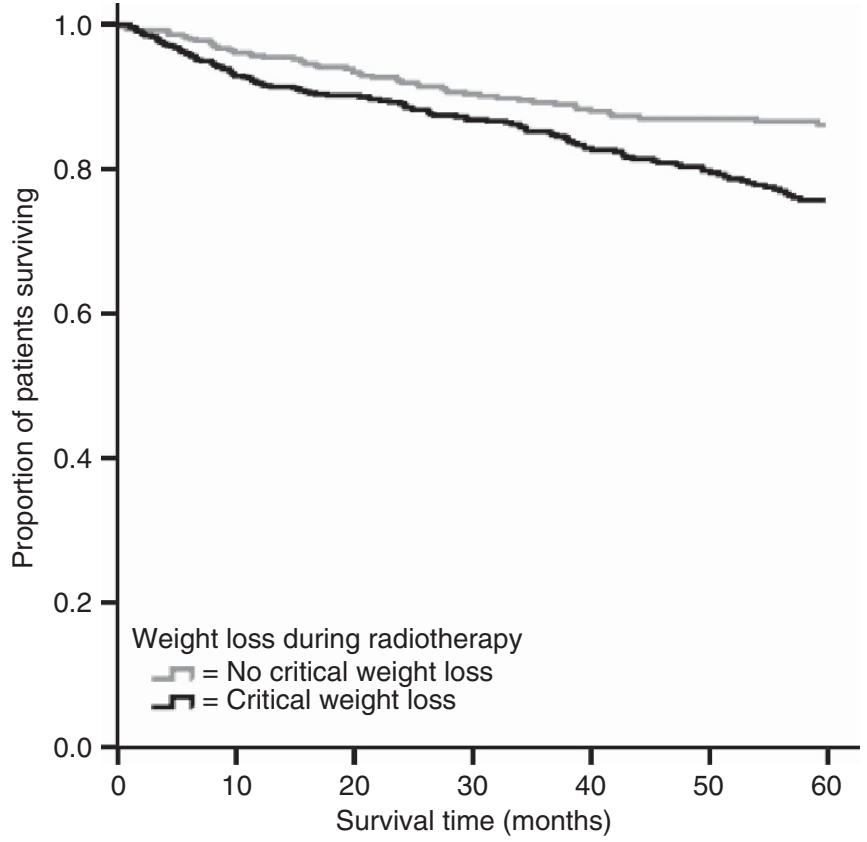

Figure 3. Kaplan-Meier survival plot of disease-specific survival by weight loss during radiotherapy (log-rank test: $P=0.001$ ).

Moreover, this large study demonstrates that weight loss before radiotherapy is also independently associated with almost two-fold risk of dying.

The association between pre-treatment weight loss and diseasespecific survival has been investigated only once in a subgroup of patients with head and neck cancer (Regueiro et al, 1994). In that study, weight loss before radiotherapy was an independent predictor for disease-specific survival in patients with cancer of the oropharynx, with a hazard ratio of 2.3. We found comparable results in this mixed group of head and neck cancer patients, and this finding therefore can now be extended to the entire group of patients with head and neck cancer.

Recently, two studies investigated the impact of weight loss during radiotherapy on survival (Pai et al, 2012; Cho et al, 2013). In the study of Pai et al (2012), weight loss during radiotherapy was an independent prognostic factor for locoregional control, but not for survival. Cho et al (2013) found weight loss of $\geqslant 10 \%$ during and 1 year after treatment as an independent prognostic factor for disease-free survival (hazard ratio 2.2), but not for overall survival, in patient with cancers of the oral cavity and oropharynx).

Our results are in line with those of Cho et al (2013). We examined the association of critical weight loss during radiotherapy and 5-year overall and disease-specific survival. In the unadjusted analysis, we found that critical weight loss during radiotherapy was significantly associated with a worse 5-year overall survival, but this association disappeared after adjusting for other relevant prognostic factors. However, critical weight loss during radiotherapy was an independent prognostic factor for 5-year disease-specific survival.

The observation that patients with critical weight loss during radiotherapy have worse disease-specific survival suggests that treatment is less effective in this patient group. The direct effect of radiotherapy on cancer cell death through irreparable DNA damage is intensified by stimulating an anti-tumour immune response (Vu et al, 2010; Kwilas et al, 2012; Tong et al, 2012). The poor response to treatment might be due to an impaired immune response as a consequence of insufficient food intake in the malnourished patients. The immune system is highly dependent upon an adequate availability of amino acids (Li et al, 2007) and specific vitamins, minerals, and trace elements (Wintergerst et al,
2007; Mora et al, 2008). Deficiency of nutrients alters the immune response, even when the deficiency state is relatively mild (Chandra, 2002). We attempted to link critical weight loss and immunity in our own series. It was previously demonstrated that a severe deficiency of peripheral blood iNKT cells in patients with head and neck cancer was significantly related to poor clinical outcome, suggesting their critical contribution to anti-tumour responses in head and neck cancer patients (Molling et al, 2007). We post hoc analysed the relation between weight loss and iNKT cells and found that patients with $>5 \%$ weight loss had significantly lower numbers of $\mathrm{T}$ cells $(722 \pm 306$ vs $1162 \pm 580 \mathrm{~T}$ cells per $\mu \mathrm{l}$ in patients with $\leqslant 5 \%$ weight loss, $P=0.021$ ), and more often a low $(<25$ th percentile) iNKT cell level compared to patients with $\leqslant 5 \%$ weight loss (55\% vs $15 \%$ of patients, $P=0.004)$. Although this analysis strengthened our hypothesis, further investigation of the impact of malnutrition on immune response in cancer patients is clearly warranted.

Weight loss during radiotherapy frequently occurs in patients with head and neck cancer. In our study, the prevalence of critical weight loss during and shortly after radiotherapy was 57\%. Several different definitions are used to define malnutrition or severe weight loss (Meijers et al, 2010). Our cutoff points for critical weight loss during radiotherapy were based on the international consensus statement of the Academy of Nutrition and Dietetics and the American Society for Parenteral and Enteral Nutrition (White et al, 2012). Lower or higher cutoff points could probably decrease or increase the hazard ratios.

Although we did not reach weight stabilisation during radiotherapy with our nutritional policy, critical weight loss can be avoided. Several studies in patients with head and neck cancer showed that nutritional therapy can be effective in stabilising body weight during radiotherapy (Isenring et al, 2004; Macia et al, 1991). Our results may cautiously suggest that preventing malnutrition by nutritional therapy might exert a positive influence on causespecific survival. However, intervention studies are needed to answer the important question if prevention of weight loss indeed has an impact on survival.

Most of the previous studies on the association of pre-treatment weight loss and overall survival performed only unadjusted analyses. The drawback of unadjusted survival analyses is that confounders may disturb the relation between weight loss during radiotherapy and survival. Thus, significant differences in the unadjusted analyses may result from other confounding variables, such as tumour location and disease stage. A strength of the present study is that herein adequate adjustment for relevant prognostic factors was possible.

Some limitations of this study should be acknowledged. First, we had to exclude 172 patients (13\%) for the analysis of weight loss during radiotherapy, and these patients had a worse overall survival compared with the included patients. It is unknown whether the exclusion of those patients has affected our results, that is, the absence of an association between critical weight loss during radiotherapy and overall survival. Second, the dose distribution of radiotherapy may influence the amount of weight loss during radiotherapy. Given the number of patients we did not delineate organs at risk for weight loss, but we used target volume in general (local $v s$ unilateral neck $v$ s bilateral neck) as a surrogate for dose to the swallowing structures. In another analysis (unpublished data), we found that this provides useful information with regard to the dose distribution to the most important organs at risk. Third, despite the adjustment for important confounding variables, we were not able to adjust for comorbidity in the entire group of patients. We used the WHO performance score. In the subgroup of patients receiving chemoradiotherapy, results of the ACE-27 test (Paleri and Wight, 2002) were available and used for a subanalysis. In contrast to what we expected, comorbidity did not alter the effect of weight loss on survival. Fourth, just as in other 
studies, pre-treatment weight loss had to be recalled because patients were newly referred to the hospital. We suppose that patient might have underreported their weight loss, especially patients with the smallest amounts of weight loss who where therefore classified into the reference group. This might have lead to underestimation of the prognostic effects on survival. On the other hand, it has been demonstrated that self-reported weight is a highly sensitive method to define malnutrition (Haverkort et al, 2012). The weight loss categories in our study had large intervals, so small differences in weight loss estimation would not have lead to other classification. We therefore deem that the results might marginally be influenced by the recall method, and if so, the extent of the association between weight loss before radiotherapy and survival is probably underestimated.

In conclusion, weight loss both before and during radiotherapy are important prognostic indicators for 5-year disease-specific survival in patients with head and neck cancer. Randomised studies into the prognostic effect of nutritional intervention during radiotherapy are needed.

\section{ACKNOWLEDGEMENTS}

We would like to thank the employees of the Department of radiation oncology for data collection; Anne van Dijk for her contribution to data management; and Patricia Doornaert, Hans van der Vliet, and Ruud Brakenhoff for their valuable advice.

\section{REFERENCES}

Argiris A, Li Y, Forastiere A (2004) Prognostic factors and long-term survivorship in patients with recurrent or metastatic carcinoma of the head and neck. Cancer 101: 2222-2229.

Baracos VE (2006) Cancer-associated cachexia and underlying biological mechanisms. Annu Rev Nutr 26: 435-461.

Brookes GB (1985) Nutritional status-a prognostic indicator in head and neck cancer. Otolaryngol Head Neck Surg 93: 69-74.

Capuano G, Gentile PC, Bianciardi F, Tosti M, Palladino A, Di PM (2010) Prevalence and influence of malnutrition on quality of life and performance status in patients with locally advanced head and neck cancer before treatment. Support Care Cancer 18: 433-437.

Capuano G, Grosso A, Gentile PC, Battista M, Bianciardi F, Di PA, Pavese I, Satta F, Tosti M, Palladino A, Coiro G, Di PM (2008) Influence of weight loss on outcomes in patients with head and neck cancer undergoing concomitant chemoradiotherapy. Head Neck 30: 503-508.

Chandra RK (2002) Nutrition and the immune system from birth to old age. Eur J Clin Nutr 56(Suppl 3): S73-S76.

Cho YW, Roh JL, Jung JH, Kim SB, Lee SW, Choi SH, Nam SY, Kim SY, Kim SY (2013) Prediction of posttreament significant body weight loss and its correlation with disease-free survival in patients with oral squamous cell carcinomas. Nutr Cancer 65: 417-423.

De Cassia Braga RK, Kowalski LP, Latorre MR (2003) Perioperative complications, comorbidities, and survival in oral or oropharyngeal cancer. Arch Otolaryngol Head Neck Surg 129: 219-228.

Edge SB, Byrd DR, Compton CC, Fritz AG, Green FL, Trotti A (2010) AJCC Cancer Staging Manual. Springer.

Ehrsson YT, Hellstrom PM, Brismar K, Sharp L, Langius-Eklof A, Laurell G (2010) Explorative study on the predictive value of systematic inflammatory and metabolic markers on weight loss in head and neck cancer patients undergoing radiotherapy. Support Care Cancer 18: 1385-1391.

Frank E, Dunlop AL (2000) What does a patient's outfit weight? Fam Med 32: 595-596.

Haverkort EB, De Haan RJ, Binnekade JM, Van Bokhorst-de van der Schueren MA (2012) Self-reporting of height and weight: valid and reliable identification of malnutrition in preoperative patients. Am J Surg 203: $700-707$.
Isenring EA, Capra S, Bauer JD (2004) Nutrition intervention is beneficial in oncology outpatients receiving radiotherapy to the gastrointestinal or head and neck area. Br J Cancer 91: 447-452.

Jager-Wittenaar H, Dijkstra PU, Vissink A, van der Laan BF, van Oort RP, Roodenburg JL (2007) Critical weight loss in head and neck cancer-prevalence and risk factors at diagnosis: an explorative study. Support Care Cancer 15: 1045-1050.

Kwilas AR, Donahue RN, Bernstein MB, Hodge JW (2012) In the field: exploiting the untapped potential of immunogenic modulation by radiation in combination with immunotherapy for the treatment of cancer. Front Oncol 2: 104.

Langius JA, van Dijk AM, Doornaert P, Kruizenga HM, Langendijk JA, Leemans CR, Weijs PJ, Verdonck-de LI (2013) More than 10\% weight loss in head and neck cancer patients during radiotherapy is independently associated with deterioration in quality of life. Nutr Cancer 65: 76-83.

Langius JAE, Doornaert P, Spreeuwenberg MD, Langendijk JA, Leemans CR, Schueren MA (2010) Radiotherapy on the neck nodes predicts severe weight loss in patients with early stage laryngeal cancer. Radiother Oncol 97: 80-85.

Li P, Yin YL, Li D, Kim SW, Wu G (2007) Amino acids and immune function. Br J Nutr 98: 237-252.

Macia E, Moran J, Santos J, Blanco M, Mahedero G, Salas J (1991) Nutritional evaluation and dietetic care in cancer patients treated with radiotherapy: prospective study. Nutrition 7: 205-209.

Mehanna H, West CM, Nutting C, Paleri V (2010) Head and neck cancerPart 2: Treatment and prognostic factors. BMJ 341: c4690.

Meijers JM, van Bokhorst-de van der Schueren MA, Schols JM, Soeters PB, Halfens RJ (2010) Defining malnutrition: mission or mission impossible? Nutrition 26: 432-440.

Molling JW, Langius JAE, Langendijk JA, Leemans CR, Bontkes HJ, Van Der Vliet HJ, Von Blomberg BM, Scheper RJ, Van Den Eertwegh AJ (2007) Low levels of circulating invariant natural killer T cells predict poor clinical outcome in patients with head and neck squamous cell carcinoma. J Clin Oncol 25: 862-868.

Mora JR, Iwata M, von Andrian UH (2008) Vitamin effects on the immune system: vitamins A and D take centre stage. Nat Rev Immunol 8: 685-698.

Nayel H, el Ghoneimy E, el Haddad S (1992) Impact of nutritional supplementation on treatment delay and morbidity in patients with head and neck tumors treated with irradiation. Nutrition 8: 13-18.

Nguyen TV, Yueh B (2002) Weight loss predicts mortality after recurrent oral cavity and oropharyngeal carcinomas. Cancer 95: 553-562.

Pai PC, Chuang CC, Tseng CK, Tsang NM, Chang KP, Yen TC, Liao CT, Hong JH, Chang JT (2012) Impact of pretreatment body mass index on patients with head-and-neck cancer treated with radiation. Int J Radiat Oncol Biol Phys 83: e93-e100.

Paleri V, Wight RG (2002) Applicability of the Adult Comorbidity Evaluation27 and the Charlson indexes to assess comorbidity by notes extraction in a cohort of United Kingdom patients with head and neck cancer: a retrospective study. J Laryngol Otol 116: 200-205.

Pedruzzi PA, Kowalski LP, Nishimoto IN, Oliveira BV, Tironi F, Ramos GH (2008) Analysis of prognostic factors in patients with oropharyngeal squamous cell carcinoma treated with radiotherapy alone or in combination with systemic chemotherapy. Arch Otolaryngol Head Neck Surg 134: 1196-1204.

Pugliano FA, Piccirillo JF, Zequeira MR, Fredrickson JM, Perez CA, Simpson JR (1999) Symptoms as an index of biologic behavior in head and neck cancer. Otolaryngol Head Neck Surg 120: 380-386.

Regueiro CA, Aragon G, Millan I, Valcarcel FJ, de la TA, Magallon R (1994) Prognostic factors for local control, regional control and survival in oropharyngeal squamous cell carcinoma. Eur J Cancer 30A: 2060-2067.

Richey LM, George JR, Couch ME, Kanapkey BK, Yin X, Cannon T, Stewart PW, Weissler MC, Shores CG (2007) Defining cancer cachexia in head and neck squamous cell carcinoma. Clin Cancer Res 13: 6561-6567.

Silver HJ, Dietrich MS, Murphy BA (2007) Changes in body mass, energy balance, physical function, and inflammatory state in patients with locally advanced head and neck cancer treated with concurrent chemoradiation after low-dose induction chemotherapy. Head Neck 29: 893-900.

Soeters PB, Reijven PL, van Bokhorst-de van der Schueren MA, Schols JM, Halfens RJ, Meijers JM, van Gemert WG (2008) A rational approach to nutritional assessment. Clin Nutr 27: 706-716. 
Tong CC, Kao J, Sikora AG (2012) Recognizing and reversing the immunosuppressive tumor microenvironment of head and neck cancer. Immunol Res 54: 266-274.

Unsal D, Mentes B, Akmansu M, Uner A, Oguz M, Pak Y (2006) Evaluation of nutritional status in cancer patients receiving radiotherapy: a prospective study. Am J Clin Oncol 29: 183-188.

Van Bokhorst-de van der Schueren MAE, Van Leeuwen PAM, Kuik DJ, Klop WMC, Sauerwein HP, Snow GB, Quak JJ (1999) The impact of nutritional status on the prognoses of patients with advanced head and neck cancer. Cancer 86: 519-527.

Van Cutsem E, Arends J (2005) The causes and consequences of cancer-associated malnutrition. Eur J Oncol Nurs 9(Suppl 2): S51-S63.

Van Den Broek GB, Rasch CR, Pameijer FA, Peter E, van den Brekel MW, Tan IB, Schornagel JH, De Bois JA, Zijp LJ, Balm AJ (2004) Pretreatment probability model for predicting outcome after intraarterial chemoradiation for advanced head and neck carcinoma. Cancer 101: 1809-1817.
Vu HL, Sikora AG, Fu S, Kao J (2010) HPV-induced oropharyngeal cancer, immune response and response to therapy. Cancer Lett 288: 149-155.

White JV, Guenter P, Jensen G, Malone A, Schofield M (2012) Consensus statement: Academy of Nutrition and Dietetics and American Society for Parenteral and Enteral Nutrition: characteristics recommended for the identification and documentation of adult malnutrition (undernutrition). JPEN J Parenter Enteral Nutr 36: 275-283.

Wintergerst ES, Maggini S, Hornig DH (2007) Contribution of selected vitamins and trace elements to immune function. Ann Nutr Metab 51: 301-323.

This work is published under the standard license to publish agreement. After 12 months the work will become freely available and the license terms will switch to a Creative Commons AttributionNonCommercial-Share Alike 3.0 Unported License. 